\title{
Some Impressions of Rehabilitation Services in the U.S.A. and Canada
}

\author{
By M. F. HUMPHREY, B.Sc. (Physiotherapy) \\ Address given to the National Council for the Care of Cripples in South Afridca at its 21st Anmual General Meeting
}

I have been asked to address you on the highlights of my study visit to Canada and America. It has been difficult to be selective, because I enjoyed it all so much.

In the four months I spent there, I visited 35 hospitals, rehabilitation centres and factories making orthopaedic appliances. In August I attended the 3rd International Prosthetics Course in New York, and in September the 8th International Congress for the Welfare of Cripples.

I had planned to see as many rehabilitation centres as possible, to study vocational training and see if this could be incorporated into a rehabilitation centre, or even if it was feasible to do so, and to learn as much as I could about orthotics and prosthetics as possible, and generally to gather as much information as I could on rehabilitation.

Of all the hospitals and institutions I visited, in my opinion the Workmen's Compensation Board Hospital in Toronto is one of the most up-to-date and modern rehabilitation centres on the Continent. The building has been beautifully designed and a great deal of thought has been expended on detail, which adds to the efficiency in management and pleasant working conditions for both patients and staff. The large park-like grounds are a joy, for there is nothing that peps up the morale of a long-term bed patient more than being able to get outside away from the confining atmosphere of the ward. The large grounds also provide an opportunity for producing very realistic outdoor on-the-job situations, which are so necessary in evaluating the patient's work tolerance before he is discharged from hospital.

My stay at the Rancho Los Amigos Hospital in Los Angeles proved to be one of the highlights of all the hospitals and rehabilitation centres I visited. It was the only one that offered a comprehensive service for the disabled, that is from accident to final placement. The Rancho caters for patients who require prolonged hospital treatment. These patients are grouped into two classifications. The firstlong-term illness and convalescence, for which there are 1,700 beds. Patients in this class are generally restricted to beds and wheelchairs, and consequently require constant nursing attention in addition to medical care and treatment. The second group are those for intensive treatment. These have 300 beds. Patients treated in this area are Post-polio, Paraplegic, Arthritic and various Neuro-muscular diseases and problems. Here they participate in an intensive programme of treatment to regain lost function and ability. One hundred beds are devoted to those patients suffering from respiratory failure, usually caused by bulbar paralysis and have to be nursed in respirators. I found the treatment of these patients intensely interesting. All patients are taught glosso-pharyngeal breathing, so that they will be able to spend increasingly longer periods out of the respirator. So successful have they been that the patient, though still suffering from paralysed respiratory muscles, but who has gained the power in his limbs, is able to be up and mobile, either walking or in a wheelchair. Even those who have gained very little motor power lead a semi-independent life in a wheelchair with the aid of strategically placed artificial muscles. There is an orthotic research laboratory in the hospital and it was here I first saw the artificial muscle and how, by strategic placing it could be of immense value to the severely paralysed patient in his struggle towards independence. Not only is it used on splints, but it can be attached to a wheelchair to facilitate the application of brakes. While I was there I saw the Orthotist fitting flexor hinge splints to a woman whose only functional muscle in her limbs was the flexor hallucis longus. With this muscle she was able to operate the valve and so gain some measure of independence in feeding.
I visited the research laboratories in Berkley, Los Angeles, and Washington, and in each case my visit was much too short. I collected a number of ideas on knee-locks and backstops for calipers, which we are gradually trying out. Calipers have been my bugbear for the past five years. The time lost in having them repaired and adjusted is phenomenal.

Until recently, a fairly general attitude of the Orthotist and Prosthetist seems to have been to produce a good piece of engineering without bothering too much about whether the appliance is comfortable or easy to manage and apply. I an very glad to report that the University of California and the Army Prosthetics Research Laboratory in Washington are remedying this state of affairs. This has been largely due to the introduction of the science of Bio-mechanics, started when it was found necessary to evaluate the stresses and strains to which the human body could be subjected when launched into space. Fortunately some of these new bio-mechanical engineers are now devoting their knowledge to more earthly matters. The greatest strides have been made in Prosthetics. I was fortunate indeed to be selected to attend the Third International Prosthetics Course in New York. The numbers were limited to 20 doctors, most of whom were Orthopaedic Surgeons, eight physiotherapists, two occupational therapists and eight orthotists.

I have never worked so hard in all my life, nor have I attended a course where each and every lecture was of such a high standard. I think the only people who worked harder than we did were the prosthetists who had to turn out three complete prostheses in ten days, using materials with which the majority were unfamiliar, the most important of these being a compound of fibre glass and polyesteresins, used in the production of upper extremity prosthesis, and for the closely moulded sockets needed for the lower extremity. These plastics provide an ideal medium as it is incredibly tough and as its consistency can be varied from a substance that is very hard and rigid to one that is soft and pliable. Its use has a great many advantages. The materials are relatively cheap. No machinery, in addition to that found in a very modest workshop, is required. The production is simple and requires only intelligent application, patience and practice. The subjects covered included Surgery, Bio-mechanics, Fabrication of Prostheses (including a certain amount of practical work), Harnessing, Fitting and Training, together with gaining a working knowledge of everything.

We have a number of sheltered workshops, but 1 don't know of any institution in our area that trains a disabled man to do a job which will fit him or her for employment in outside industry.

By Vocational Training I do not necessarily mean training a man to be a fully qualified tradesman, as we all know most trades require a man to be apprenticed and to attend a technical school, but you can teach a man who, for instance, has been employed in the building industry all his life and who has now lost the use of a hand or leg, a useful trade by which he can earn a living. For example, furniture repair or to operate a machine.

A bilities Incorporated is a workshop on Long Island started by Henry Viscardi, himself a congenital bi-lateral amputee, from a very small beginning with a couple of disabled men. Abilities Incorporated has grown to a very large and expanding business. This is no charitable organisation, and each man and woman must get himself to and from work under his own steam. For practical reasons most workers live near the factory. Applicants living too far away are not considered. Most of the work undertaken is contract work for industries in and around New York. Any disabled person, provided he proves that he is willing to do 
a full day's work, is considered for a vacancy. I saw one man wheeling himself round on a stretcher, and yet 1 was assured that he was a very good worker.

When I visited Abilities I walked round the car park and examined some of the conversions. I think some of the adaptations would have horrified our traffic department, but they were very ingenious. Of the 273 people employed at Abilities 52 per cent drove their own cars, 41 per cent obtained lifts with other members of staff, 2 per cent were taken to work by a member of their family, 1 per cent travelled to work by train and the other 2 per cent either came by train or bus. No transport was provided by the factory.

At the May. T. Morrison Centre in San Francisco routine Physiotherapy and Occupational Therapy treatments are carried on. An interesting feature about this Centre is that there is a Vocational Evaluation Service, which carries out work sampling or job simulation testing under the professional supervision of a Physiotherapist, Occupational Therapist and an Industrial Engineer. The work sampling procedure takes place over a period of several days. Tests have been devised which will fit into the Directory of Occupational Titles prepared by the United States Employment Services. This service has been most useful to the Local Department of Labour and is used extensively by insurance carriers for assessing the client's disability. In these cases the patient can be placed in a work situation in the Centre's workshop and watched and assessed for a further period, and with luck eventually placed in industry. The Institute for Crippled and Disabled in New York is run on similar lines to the May T. Morrison, although this is a much bigger organisation. An interesting feature of both is group discussion of individual patients in an endeavour to assess their ability, progress and eventual placement. I sat in at a number of these meetings where the personnel varied in number from 10 to 25 , and it occurred to me that perhaps in some cases the patient was suffering from an overdose of attention.

I found that the approach to the vocational training and employment of the handicapped at these Centres was most stimulating, but it was at the Goodwill Industries in Oklahoma City that I found a solution to the training and employment that appealed to me very strongly, particularly in that it could be so easily adapted to our own needs. It is a business, not a sheltered workshop, which is run wholly on scrap material-old clothes, furniture, household appliances, building material, scrap iron, books and magazines and many other commodities. These are collected, repaired and then resold in their own shops and in sub-economic areas. The workshop pays its own way and is not subsidized by Government or private enterprise. Initially a loan was obtained from the National Organization in Washington. Wages paid are very small, but conform to the minimum wage laid down by the Federal and State Wage and Hour Regulations. This is about 80 cents per hour (about 5s.) but that $5 \mathrm{~s}$. would only have the same buying power as $2 \mathrm{~s}$. in our country, which means that the minimum weekly wage would be equal to about $£ 4.0 .0$ and at sheltered employment $£ 47 \mathrm{~s}$. 6d. per week. However, there is room for advancement for those who are capable and selected cases are often helped to find jobs in outside industries. Every employee is a worker with some disability-from the manager down to the office boy. Its success is largely due to a small but discerning Board of Directors, who have succeeded in placing the right man or woman in the right job. Its success is also very largely due to a very well organized advertising campaign, whereby the whole city has been made aware of their existence and induced to help on the basis that it is good business. All articles collected are sorted and repaired. Those not in this category such as paper and iron, are sold as scrap. For clothing a baler is used to pack clothing into convenient bundles for storage until such time as it can be sorted, dry-cleaned or laundered, prior to being priced and ticketed and packed into cartons for despatch to the company's retail shops. Initially a dry cleaner was employed to teach selected personnel the trade. These in turn taught others, and many have been employed by dry cleaning establishments in the city. Ticketing is done by means of a simple punch, which in this instance was operated by an adult athetoid.

Boots and Shoes. Here again a cobbler was employed initially and trainees have in their turn taught others, and many are now employed in the City.

Furniture of all descriptions is collected and repaired, either in the Woodwork or Upholstery section. The same principle being applied as in the dry-cleaning and shoe departments. There is an electrical and radio repair shop. Trainees in this section, if they show sufficient aptitude may be drafted into another section doing contract work and "nuisance" jobs for local industry. Circuit boards are wired on a contract basis for local manufacturers. Employees working in this section are paid at a much higher rate, in fact, at the standard piece rate, as the jobs require certain technical skill. Screws, nuts and bolts are sorted for another factory - this being one of the nuisance jobs done for local industry. The intelligence level required for this job is very low indeed.

These are but a few of the activities being carried out in the re-training and employment of the disabled.

Severely disabled men and women, usually of a higher social and mental status, were carrying out the administration and duties of factory foremen. These cases are not normally admitted to a sheltered employment workshop.

At the Oklahoma Industries the director of the factory was a woman so severely disabled by Polio that she could barely drag herself round on crutches, but she was a University Graduate and had previously been unable to find employment. If this enterprise can be self-supporting in a city of some 300,000 inhabitants, where the market for second-hand goods is somewhat limited, surely in a city with over a million inhabitants and an enormous potential market for second-hand articles, an organization run on similar lines should flourish. For instance, a work-testing unit could be instituted whereby an insurance company, on payment of a small fee could get expert advice on a client who claims that, because of his disability he can no longer go back to his former employment. This would be another source of revenue for the business. The unit could also, perhaps, undertake the re-training of men for a specific job for Government or private organizations who would be prepared to take a man back after he was severely disabled, provided he could do a specific job.

I feel the answer is not to do vocational training or retraining in a hospital, but to have a separate workshop within easy reach of the rehabilitation centre. The advantage would be that the patient would be removed from the hospital atmosphere as quickly as possible. Perhaps some agreement could be reached whereby industry would undertake to re-train patients who had completed their physical training at a rehabilitation centre, or those who required work hardening or light work for a stated period and could be drafted to the maintenance squad of a factory. The personnel employed in industry could be divided into four categories, the first-those who could not be trained to do anything but the simplest repetitive tasks, and could never be placed in the outside industrial labour market. Those who could be re-trained, but because of the nature of their disability, i.e. continual breakdowns-for example the paraplegias, it would not be possible to cast on the open market. Thirdly, those who could be re-trained and eventually absorbed into industry. And lastly, a maintenance squad - those who require light work for a stated period.

In conclusion, I would like to say how very helpful and friendly I found the people. I was offered more hospitality than I was able to accept. When I returned to New York I attended the 8 th World Congress of the International Society for Rehabilitation of the Disabled and for me the highlight of this was the announcement that the Council's film "New Legs" had won 2nd prize in the Rehabilitation Film competition.

I wish to thank the National Council for the generous study grant which made possible my visit to America and Canada. 
INTRODUCTION TO A DEMONSTRATION OF GROUP PATIENTS HELD AT POST GRADUATE COURSE, CAPE TOWN, OCTOBER 1961

by Miss C. Junack, University of Cape Town, Department of Physiotherapy, Member S.A.S.P.

It is a great privilege for me to give a demonstration of Group Treatments to you.

I hope you will be very critical and by discussing the work, help us to improve our methods.

Many of you have been trained in England, where Treatment in Groups is taught and very well practised. You will have had a long spell of experience in it and I do not feel very competent to give this demonstration.

After my short practise-since the opening of the School of Physiotherapy in Cape Town, I am fully convinced that this method of treating the patient has a big and valuable place in Physiotherapy, for the following reasons:

Firstly: In my opinion the strongest point lies in the psychological effect. In company with others who have suffered in a similar way the patient is more likely to overcome his shock and depression and to cope with his disability.

We all know how important the state of mind is regarding the healing process: therefore, activities done with others are found to be of great assistance.
Secondly: It is a practical way to cope with a greater number of patients-four, six, eight, or even more can be done in the time taken to treat one or two individually: but it is not easily done if effective and adequate treatment is to be given to each member of the Group.

The difficulty lies in knowing every patient's present condition properly, and to take his specific needs into consideration.

Therefore, I wish to say that Group Treatments require considerable skill. The skill lies in quick and good observation, in the ability of arranging and organising the Class, in alert teaching, and in educating the patient to do proper exercises on his own. Exercises will be carried out by all of the Group to the best of their ability, or, if necessary, the class may split up for individual training, and combine towards the end of the treatment in a more relaxed and enjoyable way.

For the demonstration I have chosen a group of Hemiplegia, and a class of Fractured Femurs.

The Hemiplegia patients have reached the advanced stage. Needless to say a great deal of individual attention has been given, and is still being carried out, if necessary.

The patients suffering from Fractured Femurs have recently been discharged from Hospital as "In-Patients", and are in the non-weight-bearing stage. They require a certain amount of individual attention, which has been given in the class.

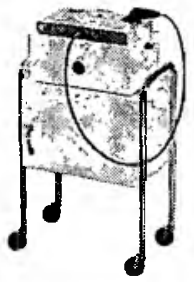

\section{THE BIRTCHER MEGASON VI ULTRASONIC UNIT}

To the more than 20,000 physicians now using ultrasonic therapy in the treatment of a host of acute and chronic conditions, this precision instrument adds new dimensions of accuracy and treatment ease.

Descriptives and medical journal reprints on request.
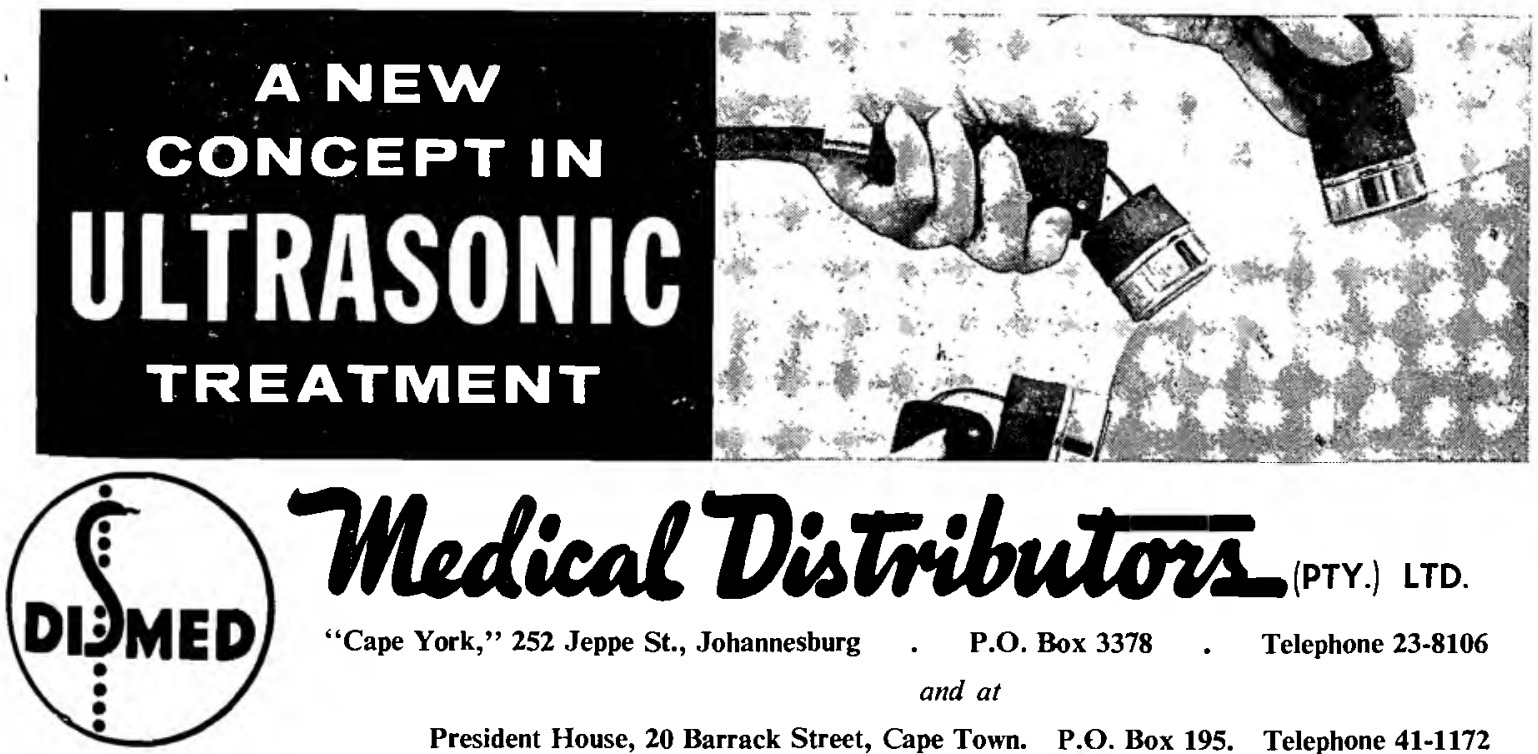

“Cape York," 252 Jeppe St., Johannesburg

P.O. Box 3378

Telephone 23-8106

and at

President House, 20 Barrack Street, Cape Town. P.O. Box 195. Telephone 41-1172 